\title{
Detection of the intragastric sites at which Helicobacter pylori evades treatment with amoxycillin and cimetidine
}

\author{
J C Atherton, A Cockayne, M Balsitis, G E Kirk, C J Hawkey, R C Spiller
}

\begin{abstract}
Treatment of Helicobacter pylori infection with amoxycillin is known to reduce the bacterial load to undetectable levels, while not eradicating the infection. It seems, therefore, that bacteria escape treatment at a 'sanctuary site'. This study examined whether such a site existed in the gastric antrum, body, or fundus. Twenty two patients with $H$ pylori infection and duodenal ulcer disease were treated for one week with amoxycillin (500 $\mathrm{mg}$ three times a day) and cimetidine (800 $\mathrm{mg}$ at night). Before treatment, $H$ pylori was detected throughout all stomachs, and ${ }^{13} \mathrm{C}$-urea breath testing at least 28 days after treatment confirmed that eradication of $\boldsymbol{H}$ pylori had occurred in no patients. While under treatment, $H$ pylori was sought by conventional methods and by polymerase chain reaction assay and was found in the gastric fundus in 13 of 22 subjects, in the body in 10 of 22 , and the antrum in three of 22: the difference between fundus and antrum was significant $(p<0 \cdot 01)$. The continued antral infection in three subjects may have resulted from generalised treatment failure as two of three had $H$ pylori detected throughout the stomach, and these two had complied relatively poorly with treatment. This study suggests that amoxycillin and cimetidine are relatively effective at clearing $H$ pylori from the gastric antrum, but that escape from treatment may occur in the gastric body, and especially the fundus.

(Gut 1995; 36: 670-674)
\end{abstract}

Division of Gastroenterology

J C Atherton

C J Hawkey

R C Spiller

Department of

Microbiology and

Public Health

Laboratory

A Cockayne

Department of

Histopathology

$M$ Balsitis

G E Kirk

University Hospital, Nottingham

Correspondence to: Dr J C Atherton, Division of Gastroenterology, University Hospital, Nottingham NG7 2UH.

Accepted for publication 15 July 1994

Treatment of Helicobacter pylori needs to be improved. The most successful current treatment is triple therapy with bismuth salts, metronidazole, and tetracycline, but this is far from perfect because of the complexity of the regimen, the frequency of side effects, and the problem of metronidazole resistance. ${ }^{12}$ The combination of amoxycillin with omeprazole may prove a possible alternative, but although promising results have been reported, ${ }^{2}$ the general experience has been disappointing. ${ }^{3-5}$ Other antibiotic combinations and newer antibiotics have also failed to provide adequate $H$ pylori eradication rates. ${ }^{67}$ This relative failure of an empirical approach to treatment prompted us to re-examine the reasons for failure of simple regimens, in the hope that improving these would eventually lead to greater treatment success.

Monotherapy with amoxycillin, whether or not combined with $\mathrm{H}_{2}$ receptor antagonists, is largely ineffective, ${ }^{89}$ but the reasons for this are unclear. $H$ pylori is always sensitive to amoxycillin in vitro so potentially it would seem a good choice of antibiotic. In vivo amoxycillin is known to suppress $H$ pylori (that is, kill enough bacteria to make standard tests negative at the end of treatment ${ }^{89}$ ) but not to eradicate it (that is, when tests are repeated a month later they are again found to be positive). Presumably a few bacteria escape treatment at a 'sanctuary site' from whence they emerge, when antibiotics are stopped, to recolonise the stomach. The problem seems, therefore, to be one of antibiotic delivery to this 'sanctuary site', and if this could be improved antibiotic monotherapy might be a realistic aim.

Possible 'sanctuary sites' for evasion from antibiotic treatment include extragastric sites (for example, dental plaque ${ }^{10}$ ), regions of the stomach (for example, the gastric fundus), and microscopic sites (for example the base of gastric pits). Sanctuary forms, like the slowly metabolising coccoid form are also a possibility and have been identified in the stomach. ${ }^{11}$ Combinations are possible, for example $H$ pylori may evade treatment in a slowly metabolising form in the gastric pits of the fundus.

In this study we aimed to determine in what region of the stomach (antrum, body, or fundus), if any, the 'sanctuary site' existed. To do this we planned to detect $H$ pylori in biopsy specimens at the end of a course of amoxycillin, and because standard biopsy based tests are usually negative in this situation ${ }^{89}$ we used a sensitive polymerase chain reaction (PCR) assay.

Twenty two subjects, mean age 42 years (range 22-68 years), 18 of whom were men, were recruited to the study. Inclusion criteria were either active duodenal ulcer (12) or previous duodenal ulcer documented by endoscopy or barium meal (10). The group with previous duodenal ulcers were included only if they had definite endoscopic scarring (2), erosive duodenitis (2), or both (6). Exclusion criteria 
included a negative antral biopsy urease test result at one hour, ingestion of antibiotics or omeprazole in the previous month or bismuth salts in the previous two months, known allergy to penicillins, previous gastrointestinal surgery, diabetes mellitus, and severe heart or lung disease.

Written informed consent was obtained from each subject. Approval was obtained from the University Hospital, Nottingham, Ethical Committee and the study was performed according to the guidelines of the Declaration of Helsinki (Hong Kong amendment).

PROTOCOL

Subjects underwent an upper gastrointestinal endoscopy and biopsy specimens were obtained from the gastric antrum, body, and fundus. They were then prescribed cimetidine (800 $\mathrm{mg}$ at night) and amoxycillin capsules (Bencard, UK: $500 \mathrm{mg}(2 \times 250 \mathrm{mg})$ thrice daily one hour before meals). Amoxycillin was taken for seven days, including the day of initial endoscopy. On the eighth day a second endoscopy was performed, in the morning, and further biopsy specimens were obtained. The subjects then continued cimetidine 800 $\mathrm{mg}$ at night for two months. During this time, but not sooner than 28 days after finishing amoxycillin, a ${ }^{13} \mathrm{C}$-urea breath test was performed.

Compliance with medication was assessed by tablet counting and by direct questioning at the second endoscopy and at the final breath test. Possible side effects of treatment were also assessed at these times by open and direct questioning, by a doctor, according to a preset questionnaire.

\section{PROCEDURE AT ENDOSCOPY}

Endoscopy was performed between 9 am and $11 \mathrm{am}$, under sedation with from 0 to $5 \mathrm{mg}$ of intravenous midazolam. Various models of endoscope were used, but all were thoroughly cleaned and disinfected between endoscopies. This involved vigorous internal and external brushing using a neutral detergent, and then being put into an endoscope washer (model EW-20, Olympus Optical Company Limited, Tokyo, Japan) and given a further seven minute wash with neutral detergent and four minute disinfection with $2 \cdot 2 \%$ glutaraldehyde.

After initial endoscopic assessment, four biopsy specimens were obtained from each of the following areas of the stomach; gastric fundus (high in the fundal vault), body (at $45-50 \mathrm{~cm}$ on the greater curve), and antrum (2-4 cm from the pylorus). A full endoscopic assessment of the upper gastrointestinal tract was then carried out. Various measures were taken to minimise cross contamination of $H$ pylori between biopsy specimens from different sites. Firstly, suction was not used during the procedure until after the final biopsy specimen had been taken. Secondly, biopsy forceps were changed between sites. Thirdly, samples were always taken in the order fundus, body, antrum. This third point meant that any cross contamination between sites was most likely to have caused false positive results in the antrum, and least likely to have done so in the fundus.

Biopsy specimens were sent for histology in formalin (two specimens) and for microbiology in nutrient broth (one specimen); the microbiology specimens being processed within two hours. A further specimen was put immediately into a biopsy urease test well (CLO test, Delta West, Australia). After 24 hours the sample was removed from the gel, using a new disposable needle, transferred to a sterile $0.5 \mathrm{ml}$ microfuge tube, and stored at $-70^{\circ} \mathrm{C}$ for later analysis by PCR assay.

\section{ANALYSIS OF BIOPSY SPECIMENS}

\section{Histology}

Specimens were fixed in $10 \%$ formal calcium, processed routinely into paraffin wax, and sections were cut at $5 \mu \mathrm{m}$. Two sets of three serial sections were obtained, one set stained with haematoxylin and eosin and the other with a modified Giemsa stain. Sections were examined independently by two histopathologists.

\section{Bacterial culture}

Specimens were plated on to chocolate-blood agar, then incubated microaerophilically (in $6 \%$ oxygen and $5 \%$ carbon dioxide) at $37^{\circ} \mathrm{C}$ for 72 hours. Colonies with the typical morphology of $H$ pylori were identified and tested for oxidase, catalase, and urease activity. ${ }^{12}$

\section{Biopsy urease test}

Specimens were transferred from the biopsy forceps directly into a biopsy urease test well and buried in the agar using a sterile needle. The test was kept at room temperature for 24 hours and a colour change to pink up to this time was deemed positive.

\section{Polymerase chain reaction (PCR) assay}

Batch analysis was performed on samples stored at $-70^{\circ} \mathrm{C}$. DNA extraction was performed by boiling the biopsy specimen in $100 \mu \mathrm{l}$ of molecular biology grade water for 20 minutes, centrifuging at $13000 \mathrm{rpm}$ in a microfuge for 10 minutes, and taking the supernatant for analysis. This simple extraction procedure has been shown to be effective in other PCR assays for $H$ pylori. ${ }^{13}$

Direct PCR was performed using the $\mathrm{Hp} 1$ and $\mathrm{Hp} 2$ primers for the $16 \mathrm{~S}$ ribosomal RNA gene of $H$ pylori described by Ho et al, ${ }^{14}$ and using the PCR conditions described by that group, with the single exception that the Taq DNA polymerase came from a different source (Northumbria Biologicals Ltd, England). Ho et al have found the assay to be specific for $H$ pylori, in that it does not detect a range of other bacteria. ${ }^{14}$ In a series of preliminary experiments we found the assay to be capable 


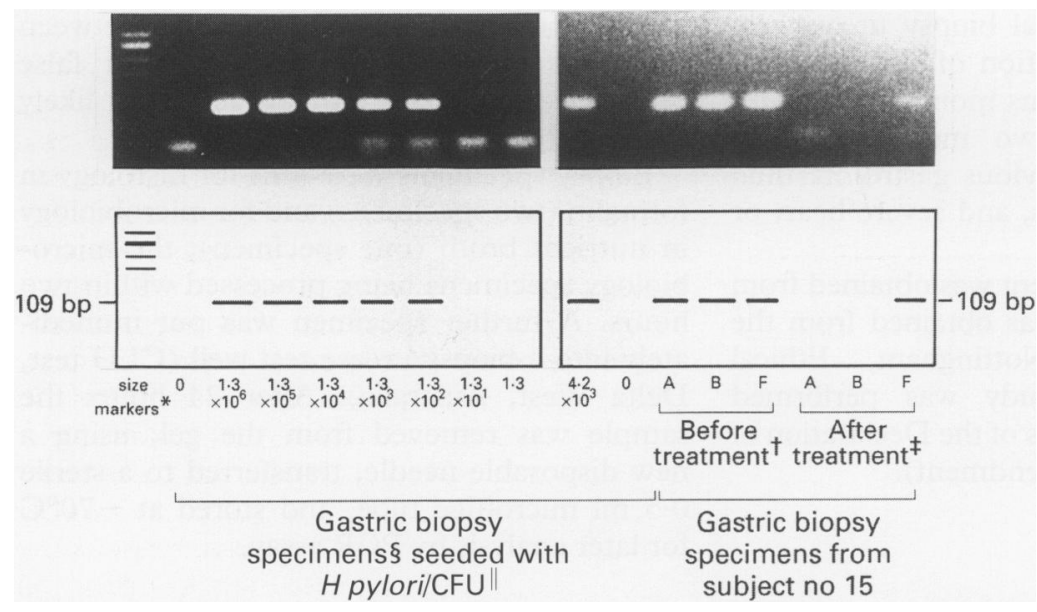

Agarose gels (2\%) showing H pylori 16S rRNA gene polymerase chain reaction (PCR) amplification products. The left panel shows PCR products from gastric biopsy specimens seeded with serial 10-fold dilutions of viable $\mathrm{H}$ pylori. The right panel shows PCR products from biopsy specimens taken from specified regions of a subject's stomach before and after amoxycillin treatment: $A=$ antrum, $B=b o d y, F=$ fundus. ${ }^{\star} \mathrm{Hae}$ III digest of phage

$X 174 R F D N A ;$ †biopsy specimens obtained immediately before starting treatment (day 1); $\ddagger$ biopsy specimens obtained on the day after the final amoxycillin dose (day 8); $\$ \mathrm{H}$ pylori negative gastric biopsy specimens; ||colony forming units.

of detecting DNA from as little as 130 viable bacteria seeded back into a gastric biopsy specimen (Figure). Consistent detection of 4200 viable bacteria was achieved when seeded specimens were used as positive controls during analysis of clinical samples and it is likely that smaller numbers would often have been detected. A range of negative controls, including $H$ pylori negative biopsy specimens, were used.

Analysis of PCR products was by gel electrophoresis in a $2 \%$ agarose gel stained with ethidium bromide and run with molecular weight markers consisting of a Hae III digest of phage X174RF DNA (Gibco Life Technologies Limited, UK). PCR was considered to be positive if a single band migrating at 109 base pairs was seen (Figure). This has previously been sequenced and found to be consistent with the $H$ pylori $16 \mathrm{~S}$ rRNA gene target. ${ }^{14}$

TABLE I Detection of Helicobacter pylori by various methods, before treatment, in the three areas of interest in the stomach. Note that subjects were excluded from the study if the biopsy urease test was negative in all areas at one hour

\begin{tabular}{llll}
\hline & $\begin{array}{l}\text { Antrum } \\
(n=22)\end{array}$ & $\begin{array}{l}\text { Body } \\
(n=22)\end{array}$ & $\begin{array}{l}\text { Fundus } \\
(n=22)\end{array}$ \\
\hline Biopsy urease test & 21 & 21 & 20 \\
Histology & 17 & 13 & 13 \\
Culture & 19 & 19 & 17 \\
Polymerase chain reaction & 22 & 22 & 21 \\
Total with H pylori detected & 22 & 22 & 21 \\
\hline
\end{tabular}

TABLE II Detection of Helicobacter pylori by various methods, immediately after treatment, in the three areas of interest in the stomach. Detection in the fundus was more frequent than in the antrum $(p<0 \cdot 01)$. The difference in detection between body and antrum $(p=0.04)$ did not reach formal significance after application of the Bonferroni correction for multiple comparisons

\begin{tabular}{lllc}
\hline & $\begin{array}{l}\text { Antrum } \\
(n=22)\end{array}$ & $\begin{array}{l}\text { Body } \\
(n=22)\end{array}$ & $\begin{array}{c}\text { Fundus } \\
(n=22)\end{array}$ \\
\hline Biopsy urease test & 0 & 0 & 0 \\
Histology & 0 & 0 & 0 \\
Culture & 2 & 1 & 3 \\
Polymerase chain reaction & 3 & 10 & 12 \\
Total with $H$ pylori detected & 3 & 10 & 13 \\
\hline
\end{tabular}

${ }^{13} \mathrm{C}$-UREA BREATH TEST $\left({ }^{13} \mathrm{C}\right.$-UBT $)$

This test, performed at least four weeks after finishing antibiotic treatment, was carried out according to a standardised protocol. ${ }^{15}$ Fasted patients were given a fatty test meal, had baseline breath samples collected, and after 10 minutes were given $100 \mathrm{mg}{ }^{13} \mathrm{C}$-urea in $50 \mathrm{ml}$ water. They then lay on their left then their right side for two minutes each, and 10 minutes after urea ingestion breath sampling was begun. Breath samples were collected every five minutes for 30 minutes and pooled in a large container. At the end of the test a sample was withdrawn from the pooled collection and this was compared with the baseline value. A difference of $>5$ per mil units between baseline and pooled samples was regarded as being a positive test. ${ }^{15}$

\section{STATISTICAL ANALYSIS}

The rate of detection of $H$ pylori immediately after treatment in the three areas of the stomach was compared directly using the Fisher exact probability test. Because three direct comparisons were made (antrum with body, antrum with fundus, and body with fundus) the Bonferroni correction for multiple comparisons was applied. This reduced the conventional level at which results were regarded as significant from $p=0.05$ to $\mathrm{p}=0 \cdot 017$.

\section{Results}

Before treatment, $H$ pylori was detected in all areas of all 22 stomachs by PCR assay and at least one conventional test, with the single exception that in one gastric fundus it could not be detected (Table I). The final breath test was performed between 28 and 56 days after the end of amoxycillin dosing (mean $38 \pm 3$ days) except in a single patient who failed to attend for breath testing during this time and was tested 133 days after amoxycillin dosing. Urea breath testing was positive in all (22 of 22) subjects, indicating no eradication of $H$ pylori.

Immediately after the course of amoxycillin and cimetidine, both histology and biopsy urease test failed to detect $H$ pylori. Microbiological culture detected the organisms successfully in four of 22 patients, and PCR did so in 16 of 22 patients. PCR assay detected $H$ pylori at all sites at which it was detected by microbiological culture, with the exception of one fundus (Tables II and III).

After treatment, $H$ pylori was found significantly more frequently in gastric fundus (13 of 22) than antrum (three of 22) $(p<0.01)$. There was a trend to more frequent detection in gastric body (10 of 22) than antrum (three of 22) $(p=0.04$ not significant after application of the Bonferroni correction for multiple comparisons) (Table II). Of the three subjects in whom $H$ pylori was detected in the antrum while taking antibiotics, two had it detected throughout the stomach and one in the antrum and body. In the other subjects with detectable 
TABLE III Pattern of gastric colonisation by Helicobacter pylori detected immediately after treatment. Detection was by polymerase chain reaction (PCR) only except for the following; * one of these two subjects also had detection in antrum and fundus by culture; $\dagger$ this subject had the same pattern detected by culture; $\ddagger$ one of these subjects had detection by PCR and culture, one by culture alone, and five by PCR alone

\begin{tabular}{|c|c|c|c|c|}
\hline \multirow{2}{*}{$\begin{array}{l}\text { No of } \\
\text { areas } \\
\text { H pylori } \\
\text { detected }\end{array}$} & \multicolumn{3}{|c|}{$\begin{array}{l}\text { Pattern of distribution of } \\
\mathrm{H} \text { pylori detection }\end{array}$} & \multirow{2}{*}{$\begin{array}{l}\text { No of } \\
\text { subjects with } \\
\text { this pattern } \\
(n=22)\end{array}$} \\
\hline & Antrum & Body & Fundus & \\
\hline 3 & + & + & + & $2^{\star}$ \\
\hline \multirow[t]{2}{*}{2} & $\begin{array}{l}+ \\
+\end{array}$ & $\stackrel{+}{-}$ & $\bar{t}$ & $\begin{array}{l}1 \dagger \\
0\end{array}$ \\
\hline & - & + & + & 4 \\
\hline \multirow[t]{3}{*}{1} & + & - & - & 0 \\
\hline & - & + & - & 3 \\
\hline & - & - & + & $7 \ddagger$ \\
\hline 0 & - & - & - & 5 \\
\hline
\end{tabular}

$H$ pylori, it was found either in the fundus alone (7), body alone (3), or body and fundus (4) (Table III).

Compliance with treatment, as monitored by tablet counting, was over $90 \%$ in all but four subjects and in these it was between 80 and $90 \%$. These four subjects included both those in whom $H$ pylori was detected in all three areas of the stomach after treatment, one subject in whom it was detected in the fundus only, and one subject in whom it could not be detected.

No adverse events were reported spontaneously. On direct questioning two subjects admitted to slightly looser stool than normal (one with increased frequency from his usual one bowel action, to three bowel actions per day). Other, possibly unrelated, symptoms elicited by direct questioning were mild abdominal discomfort (two subjects), headaches (two subjects, one of whom was a subject with loose stool), and slight irritability (two subjects).

\section{Discussion}

This study has shown that after a one week course of anoxycillin and cimetidine, $H$ pylori often evade treatment in the gastric fundus and sometimes do so in the gastric body, whereas they are normally cleared from the gastric antrum. Furthermore, there are several reasons to suspect that in the three patients with continued infection of the antrum there was a more generalised failure of treatment, perhaps related to poor compliance with medication. In two of the three subjects in whom $H$ pylori was detected in the antrum, it was detected throughout the stomach and these two subjects were two of the four subjects who complied relatively poorly with treatment. Also, in two of the three subjects with $H$ pylori detectable in the antrum, it could also be detected by microbiological culture, suggesting that the remaining load of $H$ pylori may have been relatively high.

To detect the regions of the stomach containing 'sanctuary sites' we used the sensitive technique of PCR assay. There has been discussion about the validity of PCR as a detection technique for $H$ pylori, ${ }^{16}$ and for this reason we used stringent measures to ensure the accuracy of our results. Great efforts were made to exclude false positive and false negative PCR results by using a range of positive and negative controls and putting them through identical extraction and reaction procedures to the samples. Cross contamination between the different areas of the stomach was minimised by avoiding suction, changing biopsy forceps between areas, and by taking samples from fundus first and antrum last. This latter point should ensure that if contamination occurred it would be most usual in antral samples, whereas we found colonisation to be most common in fundal samples. Cross contamination between subjects is another potential possibility, as there have been recent descriptions of PCR positive specimens on endoscopes after sterilisation, ${ }^{16}$ although it is difficult to see how this could explain the regional differences that we found within the stomach. In this study cross contamination between subjects was not found to occur, as in several cases, after treatment, gastric juice was sampled through the endoscope and this was subsequently found to be negative for $H$ pylor by PCR. Whether this is because our PCR assay is less sensitive than others, or because our endoscopes are cleaned more thoroughly remains unclear.

A further potential problem with using PCR as a detection technique is that it gives no indication as to whether organisms are alive or dead, since it detects only the target sequence of bacterial DNA. However, mucus turnover in the stomach is rapid, ${ }^{17}$ so dead bacteria would be expected to be shed quickly and detection by PCR should imply current or very recent infection. Furthermore, we detected living organisms by bacterial culture at a total of six sites in four patients, and culture results agreed with PCR at five of these six sites.

Detection of $H$ pylor $i$ while under treatment was unsuccessful in five of 22 subjects, even though a subsequent breath test showed that it had not been eradicated. The most likely explanation for this is biopsy sampling error, a recognised problem. ${ }^{18} 19$ This may also explain why one subject under treatment had $H$ pylori detected in the fundus by culture but not by PCR.

At the initial endoscopy there was an incomplete correlation between detection methods, the likely explanation for which is sampling error between biopsy sites. It is not surprising that the biopsy urease test performed well, since this was the index investigation. PCR proved reassuringly sensitive compared with other tests. Culture achieved higher sensitivity than is often described and histology lower, and we have no ready explanation for this. During treatment, culture was the only standard test to detect $H$ pylori. This may be because it is not as dependent as either histology or biopsy urease test on numbers of organisms - if just one bacterium multiplies, a positive culture may ensue.

Why does $H$ pylori persist in the gastric fundus and body during treatment? One explanation, supported by preliminary studies, ${ }^{2021}$ is that delivery of amoxycillin to the mucosa in these areas is poor. Other 
possibilities are that antibiotics are less active in the acid-producing environment of the body and fundus or that the bacteria are more resistant to treatment in this environment. Whatever the explanation, it would seem likely that reformulation of old antibiotics, or development of new ones, to specifically target the gastric body and fundus should lead to more successful anti-Helicobacter treatment.

$H$ pylori infection is an enormous worldwide problem. Complicated antibiotic regimens cannot provide a practical worldwide solution. We need to know why simple regimens fail so that their effectiveness can be improved. This study provides some insight into this, in that the failure of amoxycillin/cimetidine treatment is shown to be due to escape at a 'sanctuary site' in the gastric fundus, and sometimes the body. We need to learn more, but eventually we hope that reformulation of simple antibiotics to achieve simple treatment regimens will prove a realistic aim.

1 Graham DY, Borsch GMA. The whos and whens of therapy for Helicobacter pylori. Am f Gastroenterol 1990; 85: $1552-5$.

2 Labenz J, Gyenes E, Ruhl GH, Borsch G. Amoxycillin plus omeprazole versus triple therapy for eradication of Helicobacter pylori in duodenal ulcer disease: a prospective, randomized and controlled study. Gut 1993; 34: 1167-70.

3 Bell GD, Powell KU, Burridge SM, Spencer G, Bolton G, Purser $\mathrm{K}$, et al. Omeprazole plus antibiotic combinations for the eradication of metronidazole-resistant for the eradication of metronidazole-resistant Helicobacter pylori. Alimen

4 Collins R, Beattie S, Xia HX, O'Morain C. Short report: high dose omeprazole and amoxycillin in the treatment of Helicobacter pylori-associated duodenal ulcer. Alimentary Pharmacology and Therapeutics 1993; 7: 313-5.

5 Unge P, Eriksson K, Bergman B, Carling L, Ekstrom P Gad A, et al. Omeprazole and amoxycillin in patients with duodenal ulcer: Helicobacter pylori eradication and remission of ulcers and symptoms during a 6-month follow-up. Gastroenterology 1992; 102: A183.

6 Logan RP, Gummett PA, Misiewicz JJ, Karim QM, Walker $\mathrm{MM}$, Baron JH. Two week eradication regimen for metronidazole resistant Helicobacter pylori. Alimentary Pharmacology and Therapeutics 1993; 7: 149-53.

7 Malaty H, Klein PD, Graham DY. Short report: cefprozil for the eradication of Helicobacter pylori. Alimentary Pharmacology and Therapeutics 1992; 6: 503-6.

8 Glupczynski Y, Burette A, Labbe M, Deprez C, DeReuck M, Deltenre M. Campylobacter pylori-association gas-
M, tritis: A double-blind placebo-controlled trial with amoxycillin. Am $\mathcal{f}$ Gastroenterol 1988; 83: 365-71.

9 Rauws EAJ, Langenburg W, Houthoff HJ, Zanen HC Tytgat GNJ. Campylobacter pyloridis-associated chronic active antral gastritis. A prospective study of its prevalence and the effects of anti-bacterial and anti-ulcer treatment. Gastroenterology 1988; 94: 33-40.

10 Nguyen A-MH, Engstrand L, Genta RM, Graham DY, ElZaatari FAK. Detection of Helicobacter pylori in dental plaque by reverse transcription-polymerase chain reacplaque by reverse transcription-polym
tion. 7 Clin Microbiol 1993; 31: 783-7.

11 Bode G, Malfertheiner P, Ditschuneit H. Pathogenetic implications of ultrastructural findings in Campylobacter pylori related gastroduodenal disease. Scand $\mathfrak{J}$ Gastroenterol 1988; 23 (suppl 142): 25-39.

12 Langenberg M-L, Tytgat GNJ, Schipper MEI, Rietra PJGM, Zanen HC. Campylobacter-like organisms in the stomach of patients and healthy individuals. Lancet 1984; i: 1348 .

13 Clayton CL, Kleanthous H, Coates PJ, Morgan DD, Tabaqchali T. Sensitive detection of Helicobacter pylori by using polymerase chain reaction. $\mathcal{F}$ Clin Microbiol 1992; 30: $192-200$.

14 Ho S-A, Hoyle JA, Lewis FA, Secker AD, Cross D, Mapstone NP, et al. Direct polymerase chain reaction test Mapstone NP, et al. Direct polymerase chain reaction test for detection of Helicobacter pylori in

15 Logan RPH, Dill S, Bauer FE, Walker MM, Hirscl MM, Gummett PA, et al. The European ${ }^{13} \mathrm{C}$-urea breath test for the detection of Helicobacter pylori. European fournal of Gastroenterology and Hepatology 1991; 3: 915-26.

16 Roosendaal R, Kuipers EJ, van den Brule AJC, Pena AS, Meuwissen SG, Walboomers, JM, et al. Detection of Helicobacter pylori DNA by PCR in gastrointestinal equipment. Lancet 1993; 341: 900.

17 Allen A, Carroll NJH. Adherent and soluble mucus in the stomach and duodenum. Dig Dis Sci 1985; 30: 555-625.

18 Morris A, Ali MR, Brown P, Lane M, Patton K. Campylobacter pylori infection in biopsy specimens of gastric antrum: laboratory diagnosis and estimation of gastric antrum: laboratory diagnosis and estima
sampling error. $\mathcal{f}$ Clin Pathol $1989 ; 42: 727-32$.

19 Bayerdorffer E, Oertel H, Lehn N, Kasper G, Mannes GA Sauerbruch T, et al. Topographic association between active gastritis and Campylobacter pylori colonisation f Clin Pathol 1989; 42: 834-39.

20 Lambert JR, Lancer B, Schenbin MA, King R, Turnbridge $\mathrm{J}$. Luminal amoxycillin determines gastric mucosal concentrations. Gastroenterology 1992; 100 (5): A104.

21 Lamouliatte $H$, Cogla R, Meyer M, Demotes-Mainard F, Coincon G, Quentin-Nourry C, et al. Pharmacokinetics of oral and intravenous amoxycillin in human gastric mucosa. Italian fournal of Gastroenterology 1991; 23 (suppl 2): 109 . 